\title{
Confirmatory factor analysis of the Thought Occurrence Questionnaire for Sport (TOQS) among adolescent athletes
}

\author{
ANDREW M. LANE ${ }^{1}$, CHRIS HARWOOD ${ }^{2}$, \& ALAN M. NEVILL ${ }^{1}$ \\ ${ }^{1}$ University of Wolverhampton, United Kingdom, ${ }^{2}$ Loughborough University, United Kingdom
}

(Received 08 December 2003; revised 28 fune 2004; accepted 11 October 2004)

\begin{abstract}
There is an inherent link between theory and measurement suggesting that validation of measures should be the first stage of theory testing. The aim of the present study was to cross-validate the factorial validity of the Thought Occurrence Questionnaire for Sport for use among adolescent athletes. National standard young athletes (Individual $\mathrm{N}=204$; Team $\mathrm{N}=360$ ) completed the TOQS questionnaire. Single-sample and multisample confirmatory factor analysis provided support for the psychometric integrity of the hypothesized three-factor correlated model. Multisample results demonstrated invariance for factor loadings and correlations between individual and team athletes. Internal consistency coefficients were over the .70 criterion for acceptability. Findings lend support to previous validation studies conducted on samples of adult athletes and suggest that the TOQS provides an equally valid measure for use among adolescent athletes. It is suggested that the TOQS can be used to investigate theoretical issues related to cognitive interference during competition.
\end{abstract}

Keywords: Measurement, sport, structural equations, model testing, psychological skills

Over the past 20 years, research and practice in the field of sport psychology has reinforced the importance of adopting a cognitive approach to understanding and improving athletic performance (Hanton \& Jones, 1999; Lee-Hill, 2000; Strean \& Roberts, 1992; Whelan, Mahoney, \& Meyers, 1991). The emergence of cognitive psychology in the sport domain owes a great deal to research demonstrating how levels of athletic performance can be differentiated on the quality of cognitions and subsequent affective responses reported by athletes prior to and during competition (Gould, Eklund, \& Jackson, 1992a, b; Jones \& Hanton, 1996). These studies reveal the debilitative effects of negative, irrelevant or irregular thought patterns before and during high-level competition, in contrast to the facilitative role of task-focused thinking and task-specific self-talk strategies (Gould, Finch, \& Jackson, 1993).

During the 1990s, the study of cognitions within sport psychology research was largely dominated by a multi-dimensional anxiety-based approach (Martens, Vealey, \& Burton, 1990). The subsequent focus of research in sport was the measurement, interpretation, and

Correspondence: Andrew M. Lane, School of Sport, Performing Arts and Leisure, University of Wolverhampton, School of Sport Performing Arts and Leisure, Walsall Campus, Gorway Road, Walsall, WS1 3BD, U.K. Tel: +44 (0)1902 322862 Fax: +44 (0)1902 323230. E-mail: A.M.Lane2@wlv.ac.uk 
consequences of cognitive anxiety symptoms (Jones, 1995) as one dimension (alongside somatic anxiety and self-confidence) of the multi-dimensional anxiety response. However, whilst this line of research focused on the intensity of pre-competition worries, it did not address the specific nature and content of cognitions themselves that occur before or during performance.

In an attempt to bridge the link between pre-competition stress and performance, research turned to affects and cognitions experienced during competition. In recent years, a growing body of research has examined cognitive interference during competition (Hatzigeorgiadis \& Biddle, 1999, 2001, 2002). Evidence from educational psychology demonstrates that measures of cognitive interference are linked with poor academic performance (Sarason, Sarason, \& Pierce, 1990; Sarason, Pierce, \& Sarason, 1996). Sarason et al. (1990) characterized into cognitive interference as task-irrelevant, selfpreoccupied thinking, and performance worries that detract attention from the task at hand. Performance is proposed to be debilitated by the effects of interfering thoughts distracting attention from task-relevant cues and using up cognitive resources that could be better used for task-processing (Sarason, 1984).

Studies examining the relationship between anxiety and cognitive interference in sport have provided mixed results. For example, Schwenkmezger and Laux (1986) found a strong association between trait anxiety and cognitive interference among a sample of handball players. Man, Stuchlicova, and Kindlmann (1995) found no significant associations between stressful situations and cognitive interference. Hatzigeorgiadis and Biddle (1999) argued that inconsistent findings could be attributed to using measures not validated for use in sport.

Hatzigeorgiadis and Biddle (1999) conducted a confirmatory factor analysis on the original Thought Occurrence Questionnaire (TOQ) developed by Sarason et al. (1996). Hatzigeorgiadis and Biddle (1999) used confirmatory factor analysis to test the underlying theory proposed by Sarason et al. (1996). Confirmatory factor analysis is proposed to provide a rigorous test of factorial validity as it tests the extent which data supports a theorized structure established a priori by the researcher. Until recently, researchers tended to use exploratory factor analysis as the technique of choice for demonstrating factorial validity. Exploratory factor analysis has been criticized for having too many arbitrary decisions (Biddle, Markland, Gilbourne, Chatzisarantis, \& Sparkes, 2001; Schutz, 1994; Thompson \& Daniel, 1996). Exploratory factor analysis is a theory generating technique rather than a tool for testing theory. Thompson and Daniel (1996) argued that theory development should be independent of the techniques used to test them.

Confirmatory factor analysis of the original thoughts of occurrence scale among athletes demonstrated fit indices that failed to reach acceptable levels (Hatzigeorgiadis \& Biddle, 1999). An analysis of each subscale indicated that items for "task related worries" showed poor coefficients. If researchers cannot trust the validity of existing measures, it is incumbent that researchers develop a valid measure before theoretical issues can be tested (Schutz, 1994). As an attempt to address this issue, and further research on cognitive interference in sport, Hatzigeorgiadis and Biddle (2000) developed a 17-item scale to assess three related constructs of cognitive interference. The three constructs included; (a) Performance Worries, characterized by thoughts associated with a perceived failure to attain performance goals, (b) Task-Irrelevant Thoughts, characterized by thoughts such as day dreaming, and thoughts not associated with competition, (c) Thoughts of Escape, characterized by thoughts related to removing oneself from the situation. Hatzigeorgiadis 
and Biddle (2000) argued that although these are discrete constructs, there should be a sufficient degree of association to form a single higher-order construct.

Hatzigeorgiadis and Biddle (2000) developed the Thought Occurrence Questionnaire for Sport (TOQS) over three stages. In stage one, an item pool was derived from interviews with athletes from different sports. In stage two, 15 experts examined the face validity of the scale. In stage three, factorial validity was tested using confirmatory factor analysis techniques. Results showed adequate factorial validity for the psychometric properties of the (TOQS). Cronbach alpha coefficients for estimates of internal consistency were acceptable.

The need for stringent measures becomes especially important when researchers extend a line of investigation to a new population. One population of importance to both sport psychology researchers and practitioners alike are developing adolescent athletes (Gould, Dieffenbach, \& Moffat, 2002; Weiss, 1995). This population is particularly significant given the combination of placing greater pressure to excel at a young age and the need to develop psychological skills for use in senior competition. The majority of research in youth sport has taken a social-cognitive or social-psychological perspective to understanding a variety of interpersonal and intrapersonal factors such as achievement motivation (Duda, 1987; Harwood \& Swain, 2001), self-perceptions (Weiss, McAuley, Ebbeck, \& Weise, 1990), selfevaluation criteria (Horn \& Hasbrook, 1987) and perceptions of significant others (Black \& Weiss, 1992; Duda \& Hom, 1993; Swain \& Harwood, 1996). All of these areas of study place cognition as a central component to understanding the young athlete in a competitive setting. However, limited research to date has investigated the nature of cognitions occurring in adolescent athletes that may be influenced by some of the individual differences and contextual factors noted above. A further understanding of the thought processes experienced by adolescent athletes during competition is also important in the development of attentional strategies to enhance mental skills (Gould et al., 2002). The TOQS scale could provide insightful information into the thought processing among young athletes provided the scale can be shown to be valid and internally reliable.

The purpose of the present study, therefore, was to investigate the factorial validity of TOQS among a sample of adolescent athletes using confirmatory factor analysis. Confirmatory factor analysis is proposed to provide a rigorous test of the integrity of a factor structure, an argument made more compelling when the factor structure is supported in two samples simultaneously.

Consistent with previous research (Hatzigeorgiadis \& Biddle, 2000), we hypothesized that TOQS data collected on adolescent athletes conform to a three-factor interrelated model. Three other models were tested. These included: (a) a single-factor model; (b) a three-factor uncorrelated model, and (c) a higher-order model on which subscales load onto a single second-order factor (see Hatzigeorgiadis \& Biddle, 2000). As previous research has found that higher anxiety scores are associated with playing individual sports (Martens et al., 1990), data were divided into two samples (individual athletes and team athletes) and multisample confirmatory factor analysis was used to test the factorial invariance for the best fitting model.

\section{Method}

\section{Participants}

Participants were 564 volunteer young athletes (age: $15-18$ years, male $=266$, female $=$ 298; individual $N=204$; team $N=360$ ). They were drawn from national-level training 
camps in the UK organized through a joint initiative between Nike, The Institute of Youth Sport and the Youth Sport Trust. Athletes competed in individual sports including Badminton, Fencing, Squash and Triathlon and team sports including Hockey, Lacrosse, Rugby, and Volleyball. It is important to recognize the level of performance at which the athletes competed. To attend these national training camps, athletes needed to be selected by their respective National Governing Bodies.

\section{Measures}

The TOQS is a 17-item questionnaire that comprises three discrete subscales: Performance Worries, Situation-Irrelevant Thoughts, and Thoughts of Escape. Items are pre-fixed with the phrase "During the competition/game I had thoughts ...". The Performance Worries subscale has six items with examples being "... that we are not going to achieve our goals" and "... that the conditions (weather, temperature, pitch, atmosphere) are no good". The subscale Situation-Irrelevant Thoughts has five items with examples being "... about personal worries", and "... about what I am going to be doing later in the day". The Thoughts of Escape subscale has six items with examples being "... about stopping”, and “... I do not want to take part in this game anymore". Items are rated on a 7-point Likert scale anchored by $1=$ never and $7=$ very often. Cronbach's alpha coefficients were .90 for Thoughts of Escape, .85 for Situation-Irrelevant Thoughts, and .78 for Performance Worries (see Hatzigeorgiadis \& Biddle, 2000).

\section{Procedures}

The institution of the second author granted ethical approval. Written parental consent for participation was granted before each training camp through the Youth Sport Trust. The instructions to participants included a reminder to respond to all items and to answer each question honestly, and that data would be treated as confidential. Participants completed the questionnaire during pre-planned break sessions between training under supervision of a research assistant or coach from the respective sport.

\section{Model testing}

Confirmatory factor analysis (CFA) using EQS V5 (Bentler \& Wu, 1995; Bentler, 1995) was used to test the four models. Model parameters were estimated using the Maximum Likelihood method. As psychometric data have a tendency to be not normally distributed, attention was given to the Mardia coefficient. If Mardia values showed significant deviation from normality, the Satorra-Bentler Scaled statistics (Robust) would be used as these have been found to perform adequately under such conditions (Bentler, 1995).

Based on suggestions by $\mathrm{Hu}$ and Bentler (1999), a two-index strategy was used. The Robust Comparative Fit Index (RCFI: Bentler, 1995) was used as an incremental fit index to test the adequacy of model fit. The RCFI is based on comparisons between the hypothesized model and a null model (in which there are no relationships among the observed variables) and are not influenced by sample size. Kline (1998) proposed that values for the RCFI less than .90 indicate that the hypothesized model could be substantially improved, whereas $\mathrm{Hu}$ and Bentler (1999) suggested that, in most circumstances, values should approach .95, the criterion for acceptability used in the present study. 
The second fit index used to assess model fit was the Root Mean Square Error of Approximation (RMSEA: Steiger, 1990). The RMSEA indicates the mean discrepancy between the observed covariances and those implied by the model per degree of freedom, and therefore has the advantage of being sensitive to model complexity. A value of .05 or lower indicates a good fit and values up to .08 indicate an acceptable fit (Browne \& Cudeck, 1993). Hu and Bentler (1999) argued that a good fitting model should show acceptable fit on both fit indices.

The best fitting model was tested in individual and team samples independently, and then simultaneously using multisample CFA. Multisample CFA tests the extent to the invariance of relationships found in two samples, and is proposed to provide a rigorous test of specified relationships within the measurement model (Bentler, 1995; Tabachnick \& Fidell, 1996). Multisample analysis was conducted in three stages. First, a baseline unconstrained model was tested. Second, the hypothesis that factor coefficients are invariant across samples was tested by placing equality constraints on factor loadings. Third, the hypothesis that relationships between factors will be invariant across groups was tested. In the present study, it is suggested that factor loadings will not be significantly different across samples, demonstrated by acceptable incremental fit indices over .95 .

\section{Results}

Mardia values showed that the data deviated significantly from normality (Mardia $=78.78$ ), hence the decision was to use the Robust Maximum Likelihood estimation method. CFA results provided support for the three-factor correlated model $(\mathrm{RCFI}=.97$; RMSEA $=.05)$ and the higher-order model $(\mathrm{RCFI}=.96$; RMSEA =.05). No support was found for the single-factor model $(\mathrm{RCFI}=.76$; RMSEA $=.13$ ) or the three-factor uncorrelated model $(\mathrm{RCFI}=.85 ; \mathrm{RMSEA}=.10)$. Therefore, results indicated that the three-factor correlated model showed the best fit, albeit marginally.

Confirmatory factor analysis results for individual and team athletes demonstrated that fit indices were comparable, and importantly, the RCFI fit index was greater than the .95 (Hu \& Benter, 1999) fit index criterion and the RMSEA lower than .08 (Browne \& Cudeck, 1993) (see Table I). As single sample results showed support for the hypothesized model, multisample CFA was used to test the invariance of the relationships between individual and team samples. Multisample results indicated support for the baseline unconstrained model and the constrained factor loadings model with the RCFI being equal to the .95 for acceptable fit and the RMSEA results being below the .08 criterion (see Table I). However, with multisample analysis, the key results derive from the multivariate Lagrange Multiplier test. Results indicated that factor loading for the items “... about what I'm going to do

Table I. Single Sample and Multisample Confirmatory factor analysis of the Thoughts of Occurrence Questionnaire for Sport.

\begin{tabular}{lccccc}
\hline & & & \multicolumn{3}{c}{ Multisample } \\
\cline { 4 - 6 } $\begin{array}{l}\text { Fit } \\
\text { Indices }\end{array}$ & $\begin{array}{c}\text { Individual } \\
(N=204)\end{array}$ & $\begin{array}{c}\text { Team } \\
(N=360)\end{array}$ & Unconstrained & $\begin{array}{c}\text { Constrained } \\
\text { factor loadings }\end{array}$ & $\begin{array}{c}\text { Constrained factor } \\
\text { loadings and correlations }\end{array}$ \\
\hline RCFI & .98 & .97 & .96 & .95 & .95 \\
RMSEA & .06 & .05 & .04 & .04 & .04 \\
\hline
\end{tabular}

Note. $\mathrm{RCFI}=$ Robust Comparative Fit Index; RMSEA = Root Mean Square Error of Approximation. 
later in the day" $\left(\chi^{2}=5.40, p<.05\right)$ and ".. that other competitors are better than me" $\left(\chi^{2}=4.83, p<.05\right)$ differed significantly between individual and team samples. It could be argued that these $\chi^{2}$ values are relatively low given the sample size and the complexity of the model.

Standardized factor loadings and error variances for TOQS scores showed support for the notion that items load onto their hypothesized subscale (see Table II). Significant correlations were evidenced between subscales (Situation-Irrelevant Thoughts and Performance Worries, Individual $r=.71, p<.01$; Team $r=.63, p<.01$; Thoughts of Escape and Performance Worries; Individual $r=.61, p<.01$; Team $r=.68, p<.01$; and Thoughts of Escape and Situation-Irrelevant Thoughts, individual $r=.61, p<.01$; Team $r=.61$, $p<.01)$. Alpha coefficients for the TOQS subscales were above the .70 criterion for acceptable fit suggested by Tabachnick and Fidell (1996) for both samples; Performance Worries, Individual alpha $=.77$, Team alpha $=.79$; Situation-Irrelevant Thoughts, Individual alpha $=.85$, Team alpha $=.86$; Thoughts of Escape, Individual alpha $=.86$, Team alpha $=.88$.

Descriptive statistics are contained in Table III. Mean scores for TOQS were highly comparable to data reported by Hatzigeorgiadis and Biddle (2000) with Performance Worries experienced to a moderate degree, but more frequently than Situation-Irrelevant Thoughts and Thoughts of Escape. A repeated measures analysis of variance of TOQS

Table II. Factor Loadings for Thought Occurrence Questionnaire for Sport among Individual N =204; Team N = 360 athletes.

\begin{tabular}{|c|c|c|c|c|}
\hline \multirow[b]{2}{*}{$\begin{array}{l}\text { "During the competition/game } \\
\text { I had thoughts ..." }\end{array}$} & \multicolumn{2}{|c|}{ Individual } & \multicolumn{2}{|l|}{ Team } \\
\hline & $\begin{array}{l}\text { Standardized } \\
\text { factor loading }\end{array}$ & $\begin{array}{c}\text { Error } \\
\text { variance }\end{array}$ & $\begin{array}{l}\text { Standardized factor } \\
\text { loading }\end{array}$ & $\begin{array}{c}\text { Error } \\
\text { variance }\end{array}$ \\
\hline \multicolumn{5}{|l|}{ Performance Worries } \\
\hline about previous mistakes I have made & .50 & .87 & .55 & .84 \\
\hline that I'm having a bad day & .75 & .66 & .70 & .71 \\
\hline $\begin{array}{l}\text { that the conditions (weather, temperature, } \\
\text { pitch, atmosphere) are no good }\end{array}$ & .41 & .91 & .47 & .88 \\
\hline that I am not going to achieve my goals today & .64 & .77 & .66 & .75 \\
\hline that I am not going to win this competition & .62 & .79 & .71 & .71 \\
\hline that other competitors are better than me & .63 & .77 & .71 & .70 \\
\hline \multicolumn{5}{|l|}{ Situation-Irrelevant Thoughts } \\
\hline $\begin{array}{l}\text { about other activities (e.g. shopping, } \\
\text { having tea, TV }\end{array}$ & .71 & .71 & .76 & .65 \\
\hline about what I'm going to do later in the day & .85 & .53 & .76 & .65 \\
\hline $\begin{array}{l}\text { about personal worries (e.g. school, } \\
\text { work, relations) }\end{array}$ & .70 & .72 & .72 & .69 \\
\hline about friends & .70 & .72 & .76 & .63 \\
\hline about what I'm going to do when I get home & .77 & .63 & .82 & .58 \\
\hline \multicolumn{5}{|l|}{ Thoughts of Escape } \\
\hline that I want to quit & .73 & .69 & .78 & .63 \\
\hline $\begin{array}{l}\text { that I do not want to take part in this } \\
\text { competition any more }\end{array}$ & .80 & .61 & .81 & .59 \\
\hline that I want to get out of here & .76 & .65 & .80 & .60 \\
\hline about stopping & .63 & .77 & .71 & .71 \\
\hline that I am fed-up with it & .83 & .56 & .81 & .59 \\
\hline that I cannot stand it any more & .84 & .54 & .75 & .66 \\
\hline
\end{tabular}


Table III. Descriptive Statistics for Thoughts of Occurrence Sport Questionnaire scores between Individual and Team Adolescent Athletes.

\begin{tabular}{|c|c|c|c|c|c|c|c|}
\hline & \multicolumn{2}{|c|}{ Individual } & \multicolumn{2}{|c|}{ Team } & \multirow[b]{2}{*}{$F_{1,556}$} & \multirow[b]{2}{*}{$p$} & \multirow[b]{2}{*}{$E t a^{2}$} \\
\hline & $M$ & $S D$ & $M$ & $S D$ & & & \\
\hline Performance Worries & 3.40 & 1.10 & 3.12 & 1.16 & 7.56 & .006 & .013 \\
\hline Situation-Irrelevant Thoughts & 2.48 & 1.16 & 2.08 & 1.06 & 17.83 & .000 & .030 \\
\hline Thoughts of Escape & 2.13 & 1.08 & 1.85 & 1.04 & 9.25 & .002 & .016 \\
\hline
\end{tabular}

Note. $n=204$ individual athletes and $n=360$ team athletes.

subscale scores indicated significant differences $\left(F_{2.575}=2106.95, p<.001, E t a^{2}=.88\right)$ with post hoc test indicating differences between each subscale. Multivariate analysis of variance indicated a significant difference in mean scores between individual and team sports on TOQS scores (Hotelling $T_{3,574}=.03, p<.001, E t a^{2}=.03$ ) with individual sport players reporting higher scores on Performance Worries, Situation-Irrelevant Thoughts, and Thoughts of Escape (see Table III).

\section{Discussion}

The present study investigated the validity of the TOQS scale for use with young athletes. Three models were tested. Results indicate a three-factor correlated and a higher-order model showed acceptable fit indices. Results for the single-factor and uncorrelated threefactor model showed poor fit. These results suggest that although items are part of the same conceptual framework as suggested by Hatzigeorgiadis and Biddle (2000), examination of the cognitive interference in sport construct should be conducted by exploring the interplay between the subscales of Performance Worries, Situation-Irrelevant Thoughts and Thoughts of Escape. We suggest that researchers and practitioners interpret subscale scores independently and investigate the interplay between each scale rather using a composite score of the sum of items.

Results of the present study demonstrate that the TOQS has acceptable factorial validity and internal consistency among a sample of individual athletes and team athletes adolescents athletes. Multisample confirmatory factor analysis is proposed to provide a rigorous test of the psychometric integrity of a questionnaire (Bentler, 1995). These results indicate that factorial invariance was evidenced for a highly restricted model with equality constraints being placed on factor loadings and correlations between factors.

Findings of the present study lend further support to those reported by Hatzigeorgiadis and Biddle (2000) that the TOQS is a valid measure of interfering thoughts in sport. It is argued that the extension of factorial validity of the TOQS to adolescent athletes represents an important contribution to developing research in this area. In particular, it addresses a limitation pertaining to the measurement of psychological constructs in sport and exercise psychology as suggested by Schutz (1994). In a summary of measurement issues, Schutz (1994) argued that researchers in the field have developed a plethora of scales, with each study providing evidence for its validity only for a later study to show its limitations. $\mathrm{He}$ suggested that: "Premature publication of measurement tools has led to a proliferation of psychological tests and a considerable amount of research of questionable validity" (p. 38). Schutz (1994) argued that a test should not be developed unless; (a) a clear need can be demonstrated, and (b) researchers use a rigorous set of criteria for questionnaire 
development. It is argued that the methods used in the present study and those reported by Hatzigeorgiadis and Biddle (2000) adhered to these principles. Hatzigeorgiadis and Biddle (1999, 2000) based the TOQS on sound theoretical principles developed initially from educational research and from interviews with athletes, and therefore, it should not be surprising that factorial validity of the TOQS was supported when applied to a different population.

Research could question whether Hatzigeorgiadis and Biddle (1999, 2000) needed to develop a new scale when there is already an existing measure of competition anxiety (see Martens et al., 1990). It should be emphasized that recent research has questioned the factorial validity (Cox, 2000; Cox, Martens, \& Russell, 2003; Lane, Sewell, Terry, Bartram, $\&$ Nesti, 1999) and the predictive validity of the Competitive State Anxiety Inventory-2 (Craft, Magyar, Becker, \& Feltz, 2003; Woodman \& Hardy, 2003). Both Lane et al. (1999) and Craft et al. (2003) argued that future research should focus on developing a valid and appropriate measure. Further, it is suggested that a sport-specific measure of cognitive interference in sport could: (a) help extend the literature from pre- to during-competition cognitive activation, and (b) help identify whether different kinds of thoughts have different effects.

Gould et al. (2002) argued that it is important to nurture psychological skills among emerging athletes. Development and validation of the TOQS can provide a standardized tool for assessing this process. Findings from the present study suggest that the TOQS can be used among samples of individual and team athletes, and we suggest that descriptive statistics (see Table III) could be used for comparative purposes in future research. In this particular sample of relatively elite adolescent athletes, whilst overall cognitive interference was low to moderate, the most frequent interfering thoughts were those associated with performance standards as opposed to those irrelevant to competition or about withdrawal from the contest. Whilst this profile of cognitions is not surprising given the nature of the sample, it nevertheless reinforces to practitioners the importance of giving primary attention to self-efficacy building strategies to help maintain high performance expectations in the athlete.

Several relevant lines of investigation could be conducted to extend research with the TOQS in youth sport populations. Firstly, we have limited knowledge of the relationships between cognitive interference, pre-competitive states and performance in youth sport. A great deal of research has focused on relationships between variables such as precompetitive emotional states and performance outcomes such as win/loss or achievement of a personal best performance etc. (see Beedie, Terry, \& Lane, 2000; Jones, 1995), with a relative absence into investigating how such variables influence thought processing during performance which may in turn affect performance detrimentally. Hatzigeorgiadis and Biddle (2001) provided indirect evidence of this in a follow-up study of volleyball players where interfering thoughts disrupted concentration and resulted in decreased effort amongst those athletes with lower goal attainment expectancies.

A more enterprising line of research may be to investigate the thoughts occurrence profiles of adolescent athletes longitudinally as they progress through different athletic transitions from junior to senior status. Recent research in youth sport settings has focused on the normative transitions that young athletes move through as they developmentally progress to higher standards of competition (Wylleman \& Lavallee, 2004). Examining differences in TOQS scores between junior elite age groups is one method of understanding the potential effects and pressures of these transitions. However, longitudinal idiographic research that tracks changes on a case by case basis may offer researchers a clearer insight 
into quality and quantity of cognitions that characterize a transition or move up to a higher level/age group. This information is of clear relevance to practitioners dealing with adolescent athletes entering the first year of senior competition. The validation of the TOQS in this study should provide researchers with a measure to fulfill these various lines of investigation.

In conclusion, results offer confirmatory support to the notion that the TOQS shows factorial validity for use among adolescent athletes. Future research should use the TOQS to investigate the extent to which thought processes of athletes during competition relate with other psychological measures.

\section{Acknowledgements}

The authors would like to thank Sam Barney for his helpful comments during the production of this paper. We would also like to thank the reviewers for their insightful comments. We would like to acknowledge the Institute of Youth Sport in partnership with the Youth Sport Trust (Great Britain).

\section{References}

Beedie, C. J., Terry, P. C., \& Lane, A. M. (2000). The Profile of Mood States and Athletic Performance: Two meta-analyses. Fournal of Applied Sport Psychology, 12, 49-68.

Bentler, P. M. (1995). EQS Structural equation program manual. Multivariate Software, Encino, CA.

Bentler, P. M., \& Wu, E. J. C. (1995). EQS/Windows user's guide. Multivariate Software, Encino, CA.

Biddle, S. J. H., Markland, D., Gilbourne, D., Chatzisarantis, N., \& Sparkes, A. C. (2001). Research methods in sport and exercise psychology: Quantitative and qualitative issues. Fournal of Sports Sciences, 19, 777-809.

Black, S. J., \& Weiss, M. R. (1992). The relationship between perceived coaching behaviors, perceptions of ability, and motivation in competitive age-group swimmers. Fournal of Sport and Exercise Psychology, 14, 309-325.

Browne, M. W., \& Cudeck, R. (1993). Alternative ways of assessing model fit. In K. Bollen, \& J. S. Long (Eds.), Testing structural equation models (pp. 132-162). Newbury, CA: Sage.

Cox, R. H. (2000). Confirmatory factor analysis of the Competitive State Anxiety Inventory-2. Proceedings of the Association for the Advancement of Applied Sport Psychology Conference, p. 49.

Cox, R. H., Martens, M. P., \& Russell, W. D. (2003). Measuring anxiety in athletics: The revised Competitive State Anxiety-Inventory-2. Fournal of Sport and Exercise Psychology, 25, 519-533.

Craft, L. L., Magyar, M., Becker, B. J., \& Feltz, D. (2003). Relationship between the Competitive State Anxiety Inventory-2 and sport performance. Fournal of Sport and Exercise Psychology, 25, 44-65.

Duda, J. L. (1987). Toward a developmental theory of achievement motivation. Fournal of Sport Psychology, 9, $130-145$.

Duda, J. L., \& Hom, H. (1993). Interdependencies between the perceived and self-reported goal orientations of young athletes and their parents. Pediatric Exercise Science, 5, 234-241.

Gould, D., Dieffenbach, K., \& Moffatt, A. (2002). Psychological characteristics and their development in Olympic champions. Fournal of Applied Sport Psychology, 14, 172-204.

Gould, D., Ecklund, R. C., \& Jackson, S. A. (1992a). 1988 US Olympic wrestling excellence: I. Mental preparation, precompetitive cognition and affect. The Sport Psychologist, 6, 358-382.

Gould, D., Ecklund, R. C., \& Jackson, S. A. (1992b). 1988 US Olympic wrestling excellence II: Thoughts and affect occurring during competition. The Sport Psychologist, 6, 383-402.

Gould, D., Finch, L. M., \& Jackson, S. A. (1993). Coping strategies used by national champion figure skaters. Research Quarterly for Exercise and Sport, 64, 453-468.

Hanton, S., \& Jones, G. (1999). The acquisition and development of cognitive skills and strategies: I. Making the butterflies fly in formation. The Sport Psychologist, 13, 1-21.

Harwood, C. G., \& Swain, A. B. (2001). The development and activation of achievement goals in tennis: 1. The Sport Psychologist, 15, 319-341.

Hatzigeorgiadis, A., \& Biddle, S. J. H. (1999). The effects of goal orientation and perceived competence on cognitive interference during tennis and snooker performance. Fournal of Sport Behavior, 22, 479-501.

Hatzigeorgiadis, A., \& Biddle, S. J. H. (2000). Assessing cognitive interference in sport: Development of the thought occurrence questionnaire for sport. Anxiety, Stress and Coping, 13, 65-89. 
Hatzigeorgiadis, A., \& Biddle, S. J. H. (2001). Athletes' perceptions of how cognitive interference during competition influences concentration and effort. Anxiety, Stress and Coping, 14, 411-429.

Hatzigeorgiadis, A., \& Biddle, S. J. H. (2002). Thoughts of escape during competition: relationship with goal orientations and self-consciousness. Psychology of Sport and Exercise, 3, 195-207.

Horn, T. S., \& Hasbrook, C. A. (1987). Psychological characteristics and the criteria children use for selfevaluation. Fournal of Sport Psychology, 9, 208-221.

Hu, L., \& Bentler, P. M. (1999). Cutoff criteria for fit indexes in covariance structure analysis: Conventional criteria versus new alternatives. Structural Equation Modelling, 6, 1-55.

Jones, G. (1995). More than just a game: Research developments and issues in competitive anxiety in sport. British Fournal of Psychology, 88, 449-478.

Jones, G., \& Hanton, S. (1996). Interpretation of competitive anxiety symptoms and goal attainment expectancies. fournal of Sport and Exercise Psychology, 18, 144-157.

Kline, P. (1998). Handbook of psychological testing (second edition). London: Routledge.

Lane, A. M., Sewell, D. F., Terry, P. C., Bartram, D., \& Nesti, M. S. (1999). Confirmatory factor analysis of the Competitive State Anxiety Inventory-2. Fournal of Sports Sciences, 17, 505-512.

Lee-Hill, K. (2000). Frameworks for sport psychologists. Champaign, IL: Human Kinetics.

Man, F., Stuchlikova, I., \& Kindlmann, P. (1995). Trait-state anxiety, worry, emotionality, and self-confidence in top level soccer players. The Sport Psychologist, 9, 212-224.

Martens, R., Vealey, R. S., \& Burton, D. (1990). Competitive Anxiety in Sport. Champaign, IL: Human Kinetics.

Sarason, I. G. (1984). Stress, anxiety, and cognitive interference: Reactions to test. Fournal of Personality and Social Psychology, 46, 929-938.

Sarason, I. G., Pierce, G. R., \& Sarason, B. R. (1996). Domains of cognitive interference. In I. G. Sarason, G. R. Pierce, \& B. R. Sarason (Eds.), Cognitive Interference: Theories Methods and Findings (pp. 139-152). Mahwah, NJ: Erlbaum.

Sarason, I. G., Sarason, B. R., \& Pierce, G. R. (1990). Anxiety, cognitive interference, and performance: Communication, cognition and anxiety. Fournal of Social Behavior and Personality, 5, 1-18.

Schutz, R. W. (1994). Methodological issues and measurement problems in sport psychology. In S. Serpa, J. Alves, \& V. Pataco (Eds.), International Perspectives on Sport and Exercise Psychology (pp. 35-57). Morgantown, Fitness Information Technology, Inc.

Schwenkmezger, P., \& Laux, L. (1986). Trait anxiety, worry, and emotionality in athletic competition. In C. D. Spielberger, \& R. Diaz-Guerrero (Eds.), Cross-cultural anxiety (p. 3). Washington, DC: Hemisphere.

Steiger, J. H. (1990). Structural model evaluation and modification: An interval estimation approach. Multivariate Behavioral Research, 25, 173-180.

Strean, W. B., \& Roberts, G. C. (1992). Future directions in applied sport psychology. The Sport Psychologist, 6, 55-65.

Swain, A. B., \& Harwood, C. G. (1996). Antecedents of state goals in age-group swimmers: An interactionist perspective. Fournal of Sports Sciences, 14, 111-124.

Tabachnick, B. G., \& Fidell, L. S. (1996). Using multivariate statistics (third ed). New York: Harper \& Row.

Thompson, B., \& Daniel, L. G. (1996). Factor analytic evidence for the construct validity of scores: A historical overview and some guidelines. Educational and Psychological Measurement, 56, 197-208.

Weiss, M. R. (1995). Children in sport: An educational model. In S. M. Murphy (Ed.), Sport Psychology Interventions (pp. 39-76). Champaign, IL: Human Kinetics.

Weiss, M. R., McAuley, E., Ebbeck, V., \& Wiese, D. M. (1990). Self-esteem and causal attributions for children's physical and social competence in sport. Fournal of Sport and Exercise Psychology, 12, 21-36.

Whelan, J. P., Mahoney, M. J., \& Meyers, A. W. (1991). Performance enhancement in sport: A cognitive-behavioral domain. Behavior Therapy, 22, 307-327.

Woodman, T., \& Hardy, L. (2003). The relative impact of cognitive anxiety and self-confidence upon sport performance: A meta-analysis. Fournal of Sports Sciences, 21, 443-457.

Wylleman, P., \& Lavallee, D. (2004). A developmental perspective on the transitions faced by athletes. In M. R. Weiss (Ed.), Developmental Sport Psychology: A lifespan perspective (pp. 507-527). Morgantown, WV: FIT. 